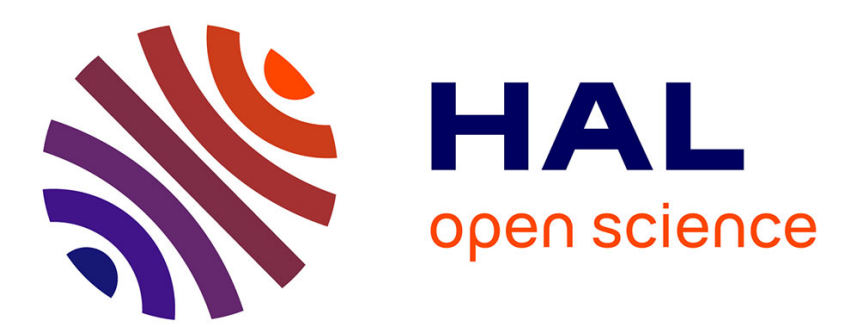

\title{
Similarity and competition in the agri-food trade among European mediterranean countries
}

Sandro Rondinella, Mariarosaria Agostino, Federica Demaria, Sophie Drogue

\section{To cite this version:}

Sandro Rondinella, Mariarosaria Agostino, Federica Demaria, Sophie Drogue. Similarity and competition in the agri-food trade among European mediterranean countries. International Trade Journal, 2019, 33 (5), pp.444-468. 10.1080/08853908.2019.1587324 . hal-02620364

\section{HAL Id: hal-02620364 https://hal.inrae.fr/hal-02620364}

Submitted on 25 May 2020

HAL is a multi-disciplinary open access archive for the deposit and dissemination of scientific research documents, whether they are published or not. The documents may come from teaching and research institutions in France or abroad, or from public or private research centers.
L'archive ouverte pluridisciplinaire HAL, est destinée au dépôt et à la diffusion de documents scientifiques de niveau recherche, publiés ou non, émanant des établissements d'enseignement et de recherche français ou étrangers, des laboratoires publics ou privés. 


\title{
Similarity and competition in the agri-food trade among European Mediterranean countries
}

\author{
Sandro Rondinella ${ }^{(\mathrm{a})}$, Mariarosaria Agostino ${ }^{(\mathrm{b})}$, Federica Demaria $^{(\mathrm{c})}$ and Sophie Drogué( ${ }^{(\mathrm{d})}$ \\ (a) Department of Economics, Statisticsl and Finance "Giovanni Anania", University of \\ Calabria, Ponte P. Bucci, Cubo 0/c, Arcavacata di Rende (CS), 87036, Italy. Email: \\ sandro.rondinella@unical.it. \\ (b) Department of Economics, Statistics and Finance "Giovanni Anania”, University of \\ Calabria, Arcavacata di Rende, Italy.Email: mariarosaria.agostino@unical.it \\ (c) Council for Agricultural Research and Economics - Research Centre for Agricultural \\ Policies and Bioeconomy, via Po, 14 - 00198 Roma, Italy, Email: \\ Federica.demaria@crea.gov.it \\ (d) UMR MOISA, INRA, Univ Montpellier, CIRAD, CIHEAM-IAMM, Montpellier \\ SupAgro, 2 place Pierre Viala, 34060 Montpellier, France. Email: \\ sophie.drogue@inra.fr
}

\begin{abstract}
Using Eurostat and OECD data on agri-food exports, this article provides a picture of the evolution in the similarity between Italian and other European Mediterranean countries' exports, before and after the recent financial crisis. Considering different indexes, the similarity is somewhat moderate and does not vary noticeably among the indexes when considering the EU-25 market. By contrast, a strong qualitative dissimilarity is recorded in the North American market. Overall, France and Spain appear more similar to Italy and likely to compete in the same agri-food market segments. The crisis seems associated to a slight modification of the exports structure.
\end{abstract}

Keywords: export structure similarity, agri-food sector, international competitiveness

\section{Postprint Version}

Sandro Rondinella, Mariarosaria Agostino, Federica Demaria \& Sophie Drogué (2019) Similarity and Competition in the Agri-Food Trade among European Mediterranean Countries, The International Trade Journal, DOI: 10.1080/08853908.2019.1587324 


\section{Introduction}

As specified by the European Commission, competitiveness is important in the European agrifood market. In the last decades, the Central and Eastern European countries' (CEECs) accession to the EU and the global economic crisis of 2008 have affected the competitiveness of the agriculture and food industry in several EU member states. The enlargement of the EU has modified trade and product demand (Bojnec and Fertő 2015; Torok and Jambor 2013; Qineti, Rajcaniova and Matejkova 2009; Zaghini 2005). Furthermore, the global economic crisis of 2008 has shaped trends in the agriculture and food industry (European Commission 2009).

Besides, other factors such as globalization, changes in consumer preferences for health, and environmental concerns are affecting the level of the EU competitiveness (Harling 2008; Wubben and Isakhanyan 2013).

In the Mediterranean area, the agriculture and food sector plays a key role, and the importance of France, Italy, and Spain is significant in the agri-food trade. The share of world agri-food trade of these economies is important; the weight of Spain was $4.4 \%$ in 2016, Italy accounted for $3.0 \%$, and France $3.4 \%$, while the other EU members play a minor role.

Countries exporting "similar" products towards the same market may be considered as competitors (De Benedictis and Tajoli 2007a, b). Trade similarity indicators are commonly employed as analytical instruments for assessing the competitiveness of groups of exporters towards a specific market. In general, the analysis of similarities aims at evaluating changes in trade similarity between countries as a result of exogenous shocks, such as the entry of new competitors into a market or political and financial upheavals (Pomfret 1981; Antimiani and Henke 2007; Antimiani et al. 2012).

The main purpose of this article is to provide a picture of the evolution in the similarity of Italian exports compared to other European Mediterranean countries' exports (France, Greece, 
Spain, and Portugal) before and after the most recent financial crisis towards two reference markets (EU-25 and North America). We focus on Italy because it is one of the biggest food producers and exporters in the EU. With a turnover of around 190 billion euros, the agri-food sector represents the second largest production sector in Italy (ISTAT 2014). The most exported agri-food products are wines, cheeses, oil, pasta, confectionery products, and cured meats, which represents the "core" of the "made in Italy" and the "Italian Sounding."

Furthermore, we are interested in the North American market as this topic is becoming relevant with the new wave of EU trade agreements.

The EU countries under scrutiny are similar in terms of natural factors (land and climate), agrifood productions, and production technologies. Furthermore, they share a common currency and trade policy. Thus, any dissimilarity in exports between Italy and its major competitors may be ascribed to factors such as product quality or greater weight of the production process into the global value chain. Three indexes are computed: the export structure similarity index (ES), the product similarity index (PSI), and the quality similarity index (QSI), which take into account different aspects of the similarity of the agri-food export structure. Such indices have been calculated both on "gross" exports and on exports in terms of value-added. The latter ones allow a more meaningful picture of the competitiveness and export capacity of an economy and its integration into the global value chain. Indeed, traditional trade statistics, recording gross flows of goods and services every time they cross a border, get into the so-called problem of "double counting or multiple counting" (Johnson 2014).

To emphasize the importance of the production process - which could increase the diversification of products and, therefore, strongly affect competitiveness in international trade - the present article takes into account the similarity as well as the quality of exports considering export flows in value added. 
Moreover, focusing on the main products exported by Italy to North America (USA and Canada) and the EU market, we verify whether the quality factor may ensure the competitiveness of agri-food exports, since apparently similar but qualitatively different products could belong to heterogeneous market segments.

Evaluating the exports performance over the periods of 2005/2006, 2008/2009, and 2011/2012, the analysis considers the years straddling the most recent global economic crisis. The agrifood sector has not received sufficient consideration from the economic literature dealing with the effects of the crisis, whereas the mobilization and comparison of the similarity index in export structure, product and quality based on trade flows data, and value added may provide some insight on the impact of the financial crises on agri-food trade. Therefore, we try to answer the following question: Did the competitiveness of Italian agri-food exports to the EU and North America change after the crisis?

According to our main findings, the similarity between Italian agri-food exports and the group of Euro-Mediterranean countries varies depending on the targeted market and the agro-food sub-sector. However, considering the European market, the level of similarity is quite moderate and the values of the three indexes are not dramatically different, with France and Spain presenting the higher values. Moreover, these countries, in the North American market, confirm their greater similarity with Italy with extremely high index values. This high similarity is not confirmed, yet, from a qualitative point of view, as the QSI values tend to zero overall. Finally, as expected, considering exports in value added, France and Spain are still the countries more similar to Italy.

Yet, results show that the economic crisis is associated with a slight modification of the exports structure and the country's competitiveness in the last period we consider. The degree of similarity in terms of product between Italy and the European Mediterranean countries 
increased in the first two periods of our analysis 2005/2006 and 2008/2009, but fell in several cases thereafter. However, an increase in the PSI does not always correspond to a decrease in the quality indicator. At the sectoral level, differences are more marked. The structure of the exports is slightly modified: the similarity in terms of product decreases but rises in goods whose features can be qualitatively equal in the EU market; the opposite is recorded in the North America. This result is interesting if we consider that Italy has the highest number of agri-food products certified by the EU. On the 31 January 2015, the Italian RDOs and GIs products registered were 278 out of a total of 1,311 (21.1\% of the total); thus, the quality factor may play a key role in determining competition among countries.

The article is organized as follows: Section 2 presents a review of the literature. Section 3 describes the structure of agri-food exports of the Euro Mediterranean countries. Trade similarity indicators are described in Section 4. Section 5 reports data. Section 6 illustrates the evidence based on the indexes computation. Finally, Section 7 concludes.

\section{Literature review}

\subsection{The application of similarity indicators}

The application of similarity indicators is manifold. In general, the analysis of similarities aims at evaluating changes in trade similarity between countries as a result of exogenous shocks, such as the entry of new competitors into a market or political and financial upheavals. Giving an economic assessment of such events is also relevant for designing appropriate economic policies. Indeed, finding potential competing countries on a specific market may recommend policies to prevent negative economic consequences such as a reduction of export flows and, consequently, the loss of market share. Adopting the ES index, the seminal contribution of Finger and Kreinin (1979) analyzes the exports similarity between the USA, Japan, EEC (European Economic Community at six countries), and some countries of Eastern Europe in different reference markets. Their data concern manufactured goods for the years from 1960 to 
the mid-1970s. Their results showed an increase of the similarity between EEC and USA and EEC and Japan in the years analyzed.

Analogously, using OECD data on agri-food trade, Pomfret (1981) applies the ES index to assess the similarity between Spain, Greece, and Portugal and several countries from North Africa and East Asia. According to the results obtained, Greece and Spain showed high similarity indices, particularly in commercial structures related to primary products.

A fundamental limitation of both works is the failure to account for differences in quality of products, which is a crucial element in the competition between countries. To face this limitation, the PSI and QSI have been included in this type of analysis, for instance, De Nardis and Traù (1999) investigate the similarity of Italian exports in the manufacturing sector relative to a large group of countries (such as G7 countries, Brazil, and some Asian countries). Looking at the results, Italy appears closer to developed countries than to developing countries in terms of exported products. Moreover, considering the quality attribute of exports, the similarity was even lower.

Antimiani and Henke (2007) analyze the similarity of the EU-15 members' exports with those of some emerging partners: the EU New Member States (NMS), Turkey and China, onto the EU-15 market. Using Eurostat data on agri-food products at the 8-digit level of the combined nomenclature, they compute three indicators (ES, PSI, QSI) for two distinct periods (1996/1997 and 2003/2004). The results show that Italian exports are more similar to those of the countries of Eastern Europe than those of Turkey and China; however, the QSI confirms that the Italian products differ greatly from a qualitative perspective. Analogously, they investigate the opportunities and risks implied by the integration of China in the world food markets. According to their results, the similarity between European countries and China is low and decreases considerably when considering the QSI (Antimiani and Henke 2006). In this regard, 
Zheng and Qi (2007) empirically analyze the structure of agricultural trade between China and the United States. Their findings show that trade between them was more complementary than competitive.

Furthermore, Antimiani et al. (2012) explore the impact of the EU enlargement process on the agro-food market, with a focus on product quality over two specific periods, 1996/1997 and 2006/2007. The values of the QSI show that the qualitative factors were explaining a third of the similarities of both commercial structures in 2006-2007 period, but only $25 \%$ in 1996-1997.

Further analysis on the degree of competition in the agricultural sector between the EU-15 countries and the eight CEECs new entrants in 2004, over the period 1995 to 2005, is carried out by Duboz and Le Gallo (2011). Computing the ES index from 1999, a growing similarity emerges; more specifically, the countries that appear potentially more affected by the integration of the CEECs are Germany and Austria - likely for the geographical proximity and France - possibly because of climatic similarity.

\subsection{The role of quality: quality and unit value in empirical models}

The discussion about the role of the quality on the agri-food sector is very present in the international trade literature, which provides new approaches to evaluate and estimate quality from trade data. The works of Fontagné et al. (2008), Crespo and Simoes (2012), and Harding and Javorcik (2009) assess the quality of exports using the unit value as a proxy. Kaitila (2010) evaluates the EU-27 countries' export structures defining a quality-adjusted similarity indicator based on unit value. Moreira, Simoes, and Crespo (2017) represent trade competition as a function of the degree of both structural similarity and total exports overlap. Structural similarity is disentangled in three dimensions: sectoral shares similarity, inter-sectoral similarity, and intra-sectoral similarity defined as the proximity in terms of quality varieties exported using unit values. Furthermore, Di Comite et al. (2011) study the relative quality of 
Chinese versus European products exported in the clothing sector after the end of the MultiFiber Arrangement, finding that European varieties exported to the US are typically sold at a higher price than identical Chinese varieties exported to the US, but this price gap is limited.

Since quality is unobservable, the previous literature is based on the idea of considering higher unit values - nominal values divided by physical volumes - as a proxy of higher quality. This approach is based on strong assumptions as differences in unit values between products might be ascribed to dissimilarities on manufacturing costs and factor prices (Khandelwal 2010).

In this regard, to estimate the quality of the products exported to the US, Khandelwal (2010) relaxes these assumptions by taking advantage of price and quantity information. ${ }^{1}$ The idea is that the higher quality of a product is attributed to those with a higher market share, conditional on price. ${ }^{2}$ The quality measures are derived from a nested logit demand system (Berry 1994) including preferences in both horizontal and vertical terms. The vertical component of the model is the quality that indicates how consumers evaluate, on average, the imported products. In particular, it captures three aspects: the time-invariant valuation that the consumer attaches to a certain imported variety, the secular time trends common across all varieties, and a varietytime specific deviation. Hence, the quality of an imported product is defined as the sum of these estimated parameters. ${ }^{3}$

Consistently with Schott (2004), who uses unit values as a proxy for quality, he shows that developed countries export higher quality products relative to developing countries.

\footnotetext{
${ }^{1}$ The author uses US product-level import data from 1989 to 2001 (Feenstra, Romalis, and Schott 2002).

2 The procedure requires no special data over those available in standard disaggregate trade data. The implementation consists in estimating separate demand curves for hundreds of manufacturing industries.

${ }^{3}$ See Khandelwal (2010) for a detailed review of this approach.
} 
Similarly, Hallak and Schott (2011), using information contained in trade balances, develop a way for decomposing countries' observed export prices into quality versus quality-adjusted components.

Basically, they assume that consumers, in choosing amid products, pay attention to price: consequently, two countries with the same export prices, but unlikely to have the same global trade balances, must have products with dissimilarities in terms of quality. Likewise, among countries with equal export prices, the country with the higher trade balance has a higher product quality. The measure of a country's product quality with respect to another country is determined by looking at data on their observed export price and including details about the demand for their products; the latter are incorporated in the trade balance with the rest of the world. However, the main issue in defining the consumer demand is that the most stable timeseries data on countries' trade balances are documented according to comparatively coarse industries rather than disaggregated products.

To circumnavigate this problem, Hallak and Schott (2011) derive an "Impure Price Index" (IPI) based on prices that are implicitly related to quality. This index aggregates countries' observed product-level export prices up to the industry level. In addition, it is separable into quality versus quality-adjusted-price components, albeit the assumption that countries' quality is constant across products within industries is required. This methodology produces estimates of quality that vary by country, industry, and year.

Hummels and Klenow (2005) use import prices and quantities to infer the cross-sectional elasticity of quality with respect to country income and size. Notwithstanding, it does not allow explicit estimation of product quality by country, sector, and year.

Furthermore, Khandelwal, Schott, and Wei (2013) define the "quality adjusted price" based on the idea that a product variety with a higher quantity is linked with higher quality, conditional 
on price. Quality is assumed as any attribute that increases consumer demand more than prices, and it is possible to estimate it indirectly through observed prices and demands specified with an explicit functional form. They assume that quality is incorporated in the consumer preferences, and the "effective quality" of an exported product $h$ shipped to destination country $c$ by firm $f$ in year $t$ is derived by dividing the residual of the estimated demand equation for a given firm $f$ 's export of a product $h$ in a destination country $c$ in year $t$ by the country-industry specific elasticity of substitution minus one. Then, the quality adjusted prices are obtained by subtracting the estimated effective quality from the observed prices. ${ }^{4}$

Curzi, Raimondi, and Olper (2014) evaluate the extent to which the reduction of import tariffs as a measure of import competition affects the quality upgrading of the food products exported to the European Union. Product quality is measured using the approach of Khandelwal (2010); furthermore, robustness checks on the main finding has been computed inferring the quality via the methodology of Khandelwal, Schott, and Wei (2013) and the classical approach of unit value. These checks confirm the main results even if with the latter method magnitudes effects are smaller in absolute terms than the baseline specification. Feenstra and Romalis (2014), in estimating quality and quality-adjusted price indexes, show, on the export side, that much of the variation in unit values is explained by quality; hence, quality adjusted prices vary much less than the raw unit values or than the quality-adjusted estimates of Hallak and Schott (2011) and Khandelwal (2010).

\section{The structure of agri-food trade of Italy and the other Mediterranean countries}

\footnotetext{
${ }^{4}$ See Khandelwal, Schott, and Wei (2013) for detailed review of this approach.
} 
As can be seen from Figures 1 and 2, the amount of agri-food exports of Italy and the other Mediterranean countries are remarkably different, but it is possible to identify a certain homogeneity between countries regarding the main products exported (Tables A1 and A2 in the Appendix). ${ }^{5}$

\subsection{EU-25 Market}

The European market is the major destination market for the agri-food exports of the five countries under scrutiny. As Figure 1 shows, France is the largest exporter, followed by Spain and Italy. In general, during the period analyzed, exports toward the EU-25 market have steadily grown. In particular, Italy registers a $36 \%$ increase of its intra-EU trade.

\section{[Figure 1]}

Table A1 in the Appendix reports the composition of the exports. We can observe a broad similarity between the countries of our sample. The main products exported from Italy to Europe are beverages (22-HS), ${ }^{6}$ which represent around $16 \%$ of total agri-food exports; followed by fruits and nuts (08-HS); preparation of cereals (19-HS); preparation of fruits and vegetables (20-HS); meat (02-HS) and dairy products (04-HS). The exports share of these products account on average for $64 \%$ of total Italian food exports towards EU-25 confirming

\footnotetext{
${ }^{5}$ The appendix can be found online at www.tandfonline.com/uitj.

${ }^{6} \mathrm{HS}$ (Harmonized System) is an abbreviated expression for the Harmonized Commodity Description and Coding System developed and managed by the World Customs Organization (WCO), used by 141 countries as a basis for the determination of tariffs and for the collection of statistics on international trade in commodities. EU members use the 'Combined Nomenclature', which extends the HS up to 10,000 clusters goods, classified with 8-digit codes (CN8). The 24 chapters of the agri-food trade are: (01) live animals, (02) meat, (03) fish, (04) dairy products, (05) products of animal origin, (06) trees and other plants, (07) edible vegetables, (08) fruits and nuts, (09) coffee and tea, (10) cereals, (11) products of the milling industry, (12) oil seeds/grains/plants/straw, (13) lac/gums/resins, (14) vegetable plaiting materials, (15) animal or vegetable fats and oils, (16) preparation of meat and fish, (17) sugar and sugar confectionaries, (18) cocoa and cocoa preparation, (19) preparation of cereals, (20) preparation of fruits and vegetables, (21) miscellaneous edible preparations, (22) beverages, (23) residues from food industries, and (24) tobacco.
} 
the leadership of the Italian agro-food. The export trends remain rather stable over time, except for fruits and nuts characterized by a constant decrease during the years under consideration.

Considering France, the main products exported to Europe are beverages, representing around $17 \%$ of total agri-food exports; followed by dairy products and cereals, which show a constant increase during these years; and finally, with lower weights meats, preparation of cereals, sugar, and sugar confectionaries. All these products make on average about $57 \%$ of total French agri-food exports; moreover, the exports trend appears stable over the years considered.

The Spanish exports composition instead is more concentrated; the first two products exported are fruits and nuts and edible vegetables accounting for, respectively, $21 \%$ and $16 \%$ of its total exports to Europe. The other main products are meats with a steady rising trend; beverages, animal or vegetable fats and oils, and fish. These six products represent on average about $70 \%$ of Spanish agri-food exports to EU-25.

The Greece situation is more unsteady. Indeed, animal or vegetable fats and oils and fruits and nuts decreased from $17.4 \%$ in $2005 / 2006$ to $9.80 \%$ in $2011 / 2012$ and from $15.75 \%$ to $12.8 \%$, respectively. Conversely, preparation of fruits and vegetables, fish, and tobacco record an important increase during the same period.

Finally, the main products exported by Portugal are beverages, showing, a noteworthy fall from $20.7 \%$ in $2005 / 2006$ to $15 \%$ in $2011 / 2012$. The other important products are fish, which account for $13 \%$ of total agri-food exports; tobacco; dairy products; and lastly, with lower weights, fruits and nuts and preparation of fruits and vegetables. Although exports show a decreasing trend in the analyzed period, the percentage of total agri-food exports remain important, about $70 \%$ on average. 


\subsection{North American market}

As shown in Figure 2, agri-food exports towards North America are smaller than the corresponding exports towards EU-25.

[Figure 2]

Over the years, the five countries show an export reduction in 2008/2009 and a significant recovery in the next period. France and Italy are the leading exporters, followed by Spain, Greece, and Portugal, which display relatively lower amounts of agri-food exports. Table A2 in Appendix shows that the exports composition of these countries is very similar, being concentrated on certain products.

The main products exported by Italy to North America are beverages, which represent on average about half of total agri-food exports; followed by animal or vegetable fats and oils, which show a negative trend; preparation of cereals; dairy products; preparation of fruits and vegetables and miscellaneous edible preparations. These products account on average for $90 \%$ of all Italian agri-food exports.

Beverages represent the main products exported by France, accounting on average for $80 \%$ of its total exports. The other main exported products are: dairy products; miscellaneous edible preparations, cocoa and cocoa preparation; lac/gum/resins; and preparation of cereals; the latter accounting for a small share of total exports. Overall, they represent on average $93 \%$ of French agri-food exports.

The Spanish exports composition is less concentrated if compared to the other counties. The main exported products are preparation of fruits and vegetables and beverages, which represent on average $50 \%$ of total Spanish agri-food exports. Animal or vegetable fats and oils 
account on average for around 15\%. Furthermore, fruits and nuts, lac/gum/resins and dairy products represent a small share of agri-food exports.

Preparation of fruits and vegetables are the main products exported from Greece to North America with an increase of exports' share from 40\% in 2005/2006 to 50\% in 2011/2012. Other products are: animal or vegetable fats and oils, beverages, and fish, which show a drastic rise in exports' share over the years. By contrast, tobacco and dairy products present a negative trend.

Portuguese exports are composed mainly of beverages, which represent around $60 \%$ of total agri-food exports; other main products exported are animal or vegetables fats and oils, products of animal origin that show a fall in the export size; conversely, preparation of fruits and vegetables, fish, and preparation of fish and meat display a positive trend.

\subsection{Exports in value added}

Looking at the agri-food exports in terms of value added (Table 1), analogously to the pattern depicted in Figures 1 and 2, we can observe a general increasing trend, the absolute values of flows remaining quite different across the sample countries.

\section{[Table 1]}

Considering the export flows in value added to the EU-25 market, France is still the leader, followed by Spain, Italy, Greece, and Portugal. Moreover, in 2011, the value added exports towards EU-25 account for 37\% of total agri-food exports for Greece, 32\% for Portugal, 30\% for Spain, 28\% for Italy, and 25\% for France.

On the other hand, the agri-food exports in terms of value added to North America appear significantly lower in comparison with those to the European market. The main exporting countries towards North America are Italy and France, followed by Spain, Portugal, and 
Greece. All countries record an increase in exports in 2008 and a subsequent decrease in the following period. In 2011, the exports in value added account for $43 \%$ of total agri-food exports for Greece, and $41 \%$ for Portugal; whereas lower values are recorded for Spain (31\%), France and Italy (both around 29\%).

In what follows, we present a deeper analysis of agri-food exports from the five EuroMediterranean countries in terms of similarity by using three indexes: the export similarity index (ES), the product similarity index (PSI), and the quality similarity index (QSI).

\section{Trade similarity indicators}

\subsection{The Finger-Kreinin Index (ES)}

The Finger-Kreinin index is used to measure the export similarity between countries (or group of countries) considering a third destination market. In other words, it compares the relative size of the export flows of both countries toward a specific target market allowing an evaluation of the competition between agri-food exports towards a specific market. The higher the similarity, the stronger the competition between countries in terms of exported goods. In the literature, this indicator is also defined as an export similarity index (ES). An advantage of this indicator, over other measures of similarity, is that it only requires international trade data, and these are available in a standardized way for all countries (Finger and Kreinin 1979).

The ES index is defined as follows:

$$
E S_{i j, h}=\left\{\sum_{k} \min \left(x_{i, h}^{k}, x_{j, h}^{k}\right)\right\} \cdot 100
$$


Where $x_{i, h}^{k}, x_{j, h}^{k}$ are, respectively, the shares of commodity (k) exported from country $i$ to country $h$ and from country $j$ to country $h^{7}$

This index measures the difference in the export structure between two countries $i$ and $j$, considering the country or market of destination $h$. If the commodity distribution of $i$ 's and $j$ 's exports are equivalent $\left(x_{i, h}^{k}=x_{j, h}^{k}\right.$ for each $k$ ), the index will take a value of 100. If $i$ 's and $j$ 's export flows are completely dissimilar (for each $x_{i, h}^{k}>0, x_{j, h}^{k}=0$, and vice versa), the ES index will take a value of zero. Therefore, the index may range from a minimum of zero, indicating the absence of any overlap between exports of $i$ and $j$ to $h$, to 100, indicating, in this case, a perfect identity of the export flows composition between $i$ and $j$ in market $h$. However, there is no possibility of determining a threshold above which the export structures between the two countries could be defined as "similar"; typically, in the literature as a rule of thumb, a threshold value of 50 has been used.

Other criticisms toward this index concern the choice of the more appropriate level of aggregation to use. It has been demonstrated that an increase in the level of commodity disaggregation generates a trend towards reduction of the index value (Pomfret 1981). Furthermore, the ES index provides a measure of similarity in the export structures between two countries in a specific market considering the share of exports, but it does not give information on the absolute dimension of the export flows. Indeed, two countries, while having a similar export structure from a product prospective, may export remarkably different amounts in absolute value, such as not to determine an actual competition. To deal with this limitation, the analysis should be complemented with another indicator, the PSI which is used to refine the analysis in relation to the absolute values of export flows (Antimiani et al. 2012).

\footnotetext{
${ }^{7}$ The shares have been computed considering as denominator the total value of exports from country $i$ to $h$ and from country $j$ to $h$, respectively.
} 


\subsection{Product Similarity Index (PSI)}

The PSI can be used to assess the real competitive pressure between countries (De Nardis and Traù 1999). This indicator measures the similarity, in a particular sector, between the absolute export dimensions of two economies (exports overlap) accounting also for the commodity flows structures. The PSI is defined by the formula:

$$
P S I=\left\{1-\left[\frac{\sum_{k}\left|X_{i, h}^{k}-X_{j, h}^{k}\right|}{\sum_{k}\left(X_{i, h}^{k}+X_{j, h}^{k}\right)}\right]\right\} \cdot 100
$$

where $X_{i, h}^{k}$ and $X_{j, h}^{k}$ are, respectively, the export flows of commodity $k$ for countries $i$ and $j$ to country $h$. The index varies between zero and 100; in the former case, the similarity of the products is null; in the latter case, the flows between the two countries are identical.

The limitation of such an index is that it might be inadequate to estimate the similarity of products; actually, goods apparently similar could be qualitatively different to the point that they do not belong to the same segment of the world demand. As a result, similar commodities may be directed to satisfy consumer groups with different types of preferences or tastes (De Nardis and Traù 1999; Antimiani and Henke 2007; Bojnec and Fertő 2010). Consequently, two apparently competing countries for a given market segment might not be competitors at all. For this reason, it is useful to define the QSI.

\subsection{Quality Similarity Index (QSI)}

In this work, we hinge on the empirical literature on intra-industry trade to select a methodology identifying qualitatively similar products; this involves splitting up the Grubel-Lloyd index into two components: the horizontal and vertical trade, based on average unit values of the goods 
concerned (Grubel and Lloyd 1971; Greenaway and Milner 1983). ${ }^{8}$ This literature assumes two basic hypotheses: i) differences in prices for a given product internationally traded reflect qualitative differences; and ii) at a sufficient disaggregation level, average unit values indices are acceptable proxies of foreign trade prices.

According to the first hypothesis, the price of an item sold on the world market is a reliable indicator of quality, as higher prices should reflect products qualitatively more valuable and price is the main information on product qualities available to consumers. The second hypothesis establishes that average unit value differences do not constitute a distorted measure of differences in international prices. Considering that average unit values (ratio between value and quantity) are often distorted due to inappropriate aggregation by product segment, the difference in the unit value of the same product that the world buys from two different countries may reflect a difference in the composition of primary products within the aggregate or the geographical diversity of the markets sources' (de Nardis and Traù 1999). An appropriate price index calculation allows isolating the differences due to real prices from those due to the mix of products and partner countries; however, this can only be done correctly if the primary product, whose average unit value is used to derive subsequent aggregations of index numbers, does not contain additional effects of composition (Aw and Roberts 1988). However, most of the empirical work, aiming at distinguishing vertical from horizontal trade analyzes trade data at a high level of disaggregation without removing the distortion in the computation of the average values for isolating "the price effect" properly from the composition effect so far described. Thus, the average unit values available are considered as proxies of prices.

\footnotetext{
${ }^{8}$ Horizontal trade represents the exchange of differentiated products, while, vertical trade is the exchange of shares of similar products but with different processing degrees. From an analytical point of view, the two kinds of trade are divided based on product average unit values. Namely, the products of the same SITC code, presenting the average unit values within a specific range, are considered qualitatively similar and are assigned to the horizontal trade; those which average unit values diverge of an amount greater than the selected amount are considered qualitatively different and consequently belong to the vertical trade (Abd-el-Rahman 1991).
} 
Analytically, to build the QSI, the share of qualitatively similar goods is extrapolated within the PSI. In the QSI calculation, a first step is the choice of similar goods to be analyzed; the $k$ commodities for which the average unit values (AUV) satisfy the following condition are regarded as similar, namely the condition of similarity in average unit values:

$$
(1-a)<\left(\frac{A U V_{k} X_{i}}{A U V_{k} X_{j}}\right)<(1-a)
$$

where $A U V_{k} X_{i}$ and $A U V_{k} X_{j}$ are the average unit values of the $k$ product exported, by country $i$ and the competing country $j$; $a$ is the dissipation factor of the average unit value in the product $k$ on the international market; such a parameter can take values ranging from 0.15 to 0.25 . The choice of a large range of dispersion reflects the need to minimize the risk of excluding from the QSI calculation goods that are qualitatively similar, but whose average unit values diverge for possible anomalies or composition effect residues. In detail, the indicator is defined as follows (Antimiani and Henke 2007):

$Q S I=\left\{1-\left[\frac{\sum_{k}\left|X_{i, h}^{k, q}-X_{j, h}^{k, q}\right|}{\sum_{k}\left(X_{i, h}^{k, q}+X_{j, h}^{k, q}\right)}\right]\right\} \cdot\left[\frac{\sum_{k}\left(X_{i, h}^{k, q}+X_{i, h}^{k, q}\right)}{\sum_{k}\left(X_{i, h}^{k}+X_{j, h}^{k}\right)}\right] \cdot 100$

where $X_{i, h}^{k, q}$ and $X_{i, h}^{k, q}$, represent, respectively, the export of country $i$ and country $j$ of the product $k$ towards country $h$, restricted to products which respect the condition of similarity average unit values previously reported; while $X_{i, h}^{k}$ and $X_{j, h}^{k}$, are the exports of country $i$ and country $j$ of product $k$ towards country $h$, respectively. ${ }^{9}$

The index varies between 0 and 100. A value of 100 means that the observed similarity index based on the PSI is an effective similarity of the quality of exported products; naturally, the

\footnotetext{
${ }^{9}$ In this formula, the second term in the equations represents the quota of qualitative similar products on overall flows of the sector. This weight was added to make the QSI index reflect the part of the PSI index value attributable to them, namely the part of the total index PSI which is effectively composed by qualitatively similar products.
} 
opposite applies when QSI is zero. ${ }^{10}$ Therefore, higher index values indicate that the qualitative similarity of the products exported increases; i.e., countries tend to export qualitatively similar products, and so they are competing with each other.

\section{Data}

The ES, PSI, and QSI are computed using data from the Eurostat database and concern agrifood exports (expressed in euros and quintals); they belong to the first 24 chapters of the HS classification. Export flows are considered at an "eight digit" merchandise disaggregation of the combined nomenclature.

The ES, PSI, and QSI are calculated comparing Italy (country $i$ ) to each other country $j$ (France, Greece, Portugal, and Spain) for two reference markets: EU-25 and North America (hereafter NAM). The time periods considered are 2005/2006, 2008/2009, and 2011/2012, and the analysis evaluates the similarity between each country pair for each class of goods.

The same analysis is carried out considering agri-food export flows in terms of value added, using data from the "Trade in Value Added" (TiVA) database, for the years: 2005, 2008, and 2011. ${ }^{11}$ Exports are reported as "domestic value added embodied in gross exports" (EXGR_DVA), expressed in millions of US dollars and representing the added value generated by exports during the production processes, as well as any added value coming upstream from domestic suppliers that is embodied in exports. ${ }^{12}$ Indeed, exports in today's global economy are

\footnotetext{
${ }^{10}$ The difference between the PSI and the weighted QSI is as well constituting a qualitative dissimilarity index (QDI) (De Nardis and Traù 1999).

${ }^{11}$ The 2015 edition of the TiVA database includes 61 countries: OECD, EU-28, G-20, most of the economies of Eastern and South-East Asia and a selection of South American countries. The years covered are 1995, 2000, 2005, and 2008 to 2011. It is worth mentioning that the TiVA database does not employ the HS classification. The relevant sectors from this database are C01T05: agriculture, forestry, hunting and fishing and C15T16: food products, beverages, and tobacco.

${ }^{12}$ For example, if China exports a microwave oven to the United States, the total export value of the microwave oven is considered as Chinese export and recorded as such in the trade account by national authorities; and from the United States perspective, the microwave oven is recorded as an import from China (and will probably require a tag "Made in China"). However, some of the inputs employed to produce the microwave oven might have been produced in and imported from different countries, for example, Thailand, Malaysia, or even the United States.
} 
based on the values of global production chains, using intermediate products imported from various industries in a number of distinct countries. ${ }^{13}$ Goods and services acquired, in general, are composed of inputs from various countries around the world. However, the flows of goods and services within these global production chains are not always evaluated efficiently through the conventional measures of international trade (Koopman, Wang, and Wei. 2008, 2014; Koopman et al. 2010). The TiVA approach circumvents the problem of "double counting" by detecting the net flow of trade between countries.

\section{Results}

\subsection{The similarity of agri-food trade between Italy and other Mediterranean} countries on the EU-25 market.

Looking at Table 2, according to the ES index, the most similar country to Italy is Spain, with an index of $36.09 \%$ in $2011 / 2012$, slightly increasing compared to the first year of the sample.

\section{[Table 2]}

The indicators concerning France and Portugal are somewhat lower, the Italy-France index tends to decrease, whilst the others tend to increase over the years. Finally, the most dissimilar country is Greece with an indicator equal to $25.55 \%$ in $2011 / 2012$, slightly increasing over time.

Moving from ES to PSI, as expected, in general values tend to reduce; Spain still remains the most similar country in terms of products similarity with a PSI of $35.41 \%$ in the last year. An

\footnotetext{
The value of these intermediates has been recorded as Chinese imports from Malaysia, Thailand, or the United States, but not linked with the exportable final product (Javorsek and Camacho 2015).

${ }^{13}$ Case studies of global value chains in industries such as electronics, apparel, and motor vehicles have provided detailed examples on the discrepancy between gross and value-added trade. According to a commonly cited study, while the Chinese factory gate price of an assembled iPod is $\$ 144$, only $\$ 4$ constitutes Chinese value added (Dedrick et al. 2010).
} 
analogous pattern emerges for France, while the product similarity with Greece and Portugal drops noticeably.

Finally, looking at the QSI, the most similar country is France with an indicator equal to 15.90 in $2011 / 2012$, even if it decreases by eight percentage points over the years. Spain follows with a QSI of 13.5 in 2011/2012, then come Greece and Portugal with much lower values.

Thus far, the analysis has been carried out considering the agri-food sector as a whole. We now compute the same indexes for the Italian products most exported: beverages, fruits and nuts, and preparations of cereals for the EU market; beverages, animal and vegetable fats and oils, and preparations of cereals for the North America destination. ${ }^{14}$

First considering the main products exported by Italy to the EU-25 (reported in Table 3), the similarity value decreases when moving from PSI to QSI.

\section{[Table 3]}

Regarding beverages - the Italian products most exported - the most similar country is Spain, followed by France; the PSI in 2011/2012 being around 44\% and 30\%, respectively. Moreover, from a qualitative point of view, Italy is totally dissimilar to all four countries, indexes tending to zero in all cases. These results show that, in this area, the quality could be a discriminating factor affecting the level of competitiveness among countries. Divergences in the QSI may be ascribed to a different quality signal or different production processes or, again, differences in the characteristics of agri-food products. Consequently, products may be similar in essence, but different in quality. Concerning fruits and nuts, the Italy-France PSI is higher (about 50\% on average over the time); Portugal is the country most dissimilar, even if the PSI increases over the years. From a qualitative perspective, greater similarity as well is recorded with France

\footnotetext{
${ }^{14}$ Tables A3-A10 in the Appendix report the indexes for each agri-food sub-sector (identified by the 24 chapters of the HS classification).
} 
(QSI is 34.40\%, in 2011/2012) and with Spain, for which the QSI rises in the last period. Considering the export of preparation of cereal, France is once again the most similar country to Italy either considering the PSI or QSI, equal to $39.5 \%$ and $30 \%$, respectively, in the last year.

\subsection{The similarity of agri-food trade between Italy and other Mediterranean countries on the North America market.}

In this section, trade similarity is calculated considering North America as the reference market. Table 4 shows the ES indexes which are very high, close to $100 \%$ representing perfect similarity.

[Table 4]

The values remain stable during the analyzed period. Moving from ES to PSI, France and Spain maintain a high degree of similarity with Italy, the index values tending to increase over the period. By contrast, the other countries' indexes drop dramatically. In addition, for all countries, the QSI tends to zero.

Put in a nutshell, observing the ES index, there is a significant similarity in exports towards North America between Italy and the considered Mediterranean countries. Yet, considering the absolute flows incorporated in the PSI, France and Spain confirm the high level of similarity. However, looking at the qualitative factor, the countries under study do not seem to compete with Italy, since the exported products are apparently bound to satisfy different market segments given their quality differentiation.

In particular, in what follows, we consider the similarity of the three main categories of agrifood products exported by Italy ${ }^{15}$ (see Table 3). According to our computations, similarity in

\footnotetext{
${ }^{15}$ Figures on all agri-food subsectors are reported in Tables A4, A6, A8, and A10 in the online Appendix.
} 
the beverages sub-sector is somewhat low, in addition, the QSI tends to zero in all cases. Good degree of similarity, instead, is registered with Spain in animal and vegetable fats and oils' exports, the PSI increasing over the years and amounting to 51.1\% in 2011/2012. This similarity is confirmed from a qualitative perspective (QSI) until 2008/2009; after that, it drops dramatically. Looking at exports of preparation of cereals, the similarity is relatively low; the Italy-France PSI is around 22\% in 2011/2012; moreover, considering the qualitative factor, the similarity between the European Mediterranean countries and Italy tends to zero, even though there is a slight increase of qualitative similarity with France and Spain in the last period.

In brief, in the three sub-sectors considered here, the similarity between Italy and France, Greece, and Portugal tends to be negligible. Furthermore, from a qualitative perspective, these countries are strongly dissimilar from Italy, thus the qualitative factor, which should guarantee products differentiation, may be a discriminating variable for increasing competitiveness in the North American market. ${ }^{16}$ An exception is Spain, which keeps with Italy a sufficient qualitative similarity for animal and vegetable fats and oils's exports. ${ }^{17}$ Besides, in this reference market, we do not record relevant changes over the years in the indexes of interest.

\subsection{Similarity in export flows in added value}

\footnotetext{
${ }^{16}$ Furthermore, the exercise might suggest that in isolated cases where the similarity increases in a particular product could cause the reduction in the amount of exports in one of the two countries. A particular case is the evaluation of similarity between Italy and Greece in tobacco's exports; it actually represented in the period 2005/2006 a significant portion of exports of Greece to North America, about 17\%, whereas, exports of such goods have been reduced over the years to reach $3 \%$ of the total export in 2011/2012. However, the similarity between Italy and Greece, considering these types of goods, significantly increased from $9 \%$ to $47 \%$ in $2008 / 2009$, with a subsequent slight decline in the third period. Moreover, exports were marked by a significant increase also in the quality factor. This could mean that the increase in similarity and, therefore, competitiveness between the two countries has in fact caused the reductions listed in the amount of tobacco exports from Greece to North America.

${ }^{17}$ In the other merchandise categories, excluding the qualitative factor, high level of similarity is found with France and Spain in exports of meat, fish and fruits and nuts; in this case PSI, Italy-France accounted for around 90\% in 2011/2012; however, these results are not confirmed by QSI. In addition, a modest level of similarity is recorded to Spain in lac/gum/resins exports; this is partially confirmed by the qualitative similarity index.
} 
In this section, we report results on two indicators (ES and PSI), as the TiVA database does not provide information on the quantities exported, thus excluding the QSI computation. The aforementioned indexes are calculated for the agri-food sector as a whole because data are not available at a more disaggregated level.

As shown in Tables 5 and 6 , in both targeted markets, the similarity between Italy and Mediterranean countries is quite high, when considering the relative shares of exports through the ES index. Besides over the period, in the EU-25 market, the Italy-Greece ES and PSI, steadily decreasing and the Italy-France PSI shows a positive trend. In addition, ES for Spain and Greece in the North American market rises steadily; conversely, the Italy-Greece PSI presents a negative trend.

[Tables 5 and 6]

Considering first exports to the EU-25 (Table 5), focusing on PSI results, Italy displays a great degree of similarity with France and Spain, with a positive trend over the years. Turning to the results in the North American market, we can see a striking similarity between Italy and France (near 100\%); a good degree of similarity is also recorded with Spain, about 52\% on average.

To summarize, considering exports in value added, there is evidence that during the years analyzed in both reference markets, the most similar countries to Italy are France and Spain, even if the latter shows a greater dissimilarity in the North American market; Portugal and Greece being dissimilar in both markets when considering the PSI.

Finally, comparing the results of this section with the results previously obtained on gross flows of exports, and taking into account the limitations of this comparison, it is clear that in the EU market, the similarity based on value added export data between Italy and Mediterranean countries is somewhat higher in both indexes. This could be due to the fact that excluding 
inputs imported from foreign markets, these countries could have a very similar productive system with Italy and, consequently, this generates a greater similarity when considering just the value added by countries.

On the other hand, in the North America market the results diverge from those mentioned earlier on gross export flows only in the case of PSI. Related to this, the similarity based on value added between Italy and France or Italy and Greece seems to be higher than that calculated on gross exports data; contrariwise, it is lower focusing on the country pairs of ItalyPortugal or Italy-Spain.

\subsection{The similarity of agri-food trade in the crisis period}

Thanks to the analysis of the three indexes over time, we may verify whether or not the economic crisis has been associated with a change in the competitiveness of the European Mediterranean countries, in the EU and North American markets.

France and Spain, overall, appear to be the main competitors of Italy in the EU-25 market, especially France concerning the qualitative factor, albeit the degree of similarity drops over time. In more detail, the ES indicator shows a slight increase compared to the first year of the analysis implying that countries after the crisis show a more similar structure of exports, except for France. The Italian exports similarity with Spain and Portugal is higher than that with Greece.

Moving from ES to PSI, the value for Spain and Portugal increases while it reduces for Greece and France. The value of PSI is largely different from ES; indeed, the PSI are smaller than the ES; therefore, the magnitudes of the flows matter. The QSI decreases showing that the crisis has probably triggered a quality-based diversification in the products exported. Indeed, a possible explanation could be that only exporters able to diversify have withstood the crisis. 
At the sectoral level, the results are heterogeneous. Our findings show for France a declining of the degree of product similarity on dairy products, cereals, sugar and sugar confectionary, flowers, beverages, fruits, and preparation of fruit and vegetables. Sectors with an evident decrease of the similarity are trees and other plants and lac, gums, and resins. It is also possible to observe a decline in the QSI; thus, compared markets compete on products that are qualitatively different.

Spain presents a slight decrease in similarity on live animals, fruits and nuts, products of the milling industry, lac/gums/resins, oils and fats, and residues from food industries. As Greece and Portugal present great dissimilarities in most of agri-food sectors, however, the similarity between Italy and Greece seems to be the most affected by the crisis. Italy gains in competitiveness compared to Greece.

In the North American market, the main competitors of Italy seem to be France and Spain, but this pattern is not confirmed by the QSI with values close to zero. Looking at the period of the crisis, the ES index for all countries is quite constant, although slight increases have been recorded in the case of PSI compared to the first period of analysis. Noticeable changes have not been found at the QSI level. Therefore, the crisis seems to have not influenced the similarity between Italy and the EU Mediterranean countries analyzed in North America.

However, at the sectoral level, the results are much more heterogenous. Our findings show an increase in the level of similarity with Greece and Portugal for several products. ${ }^{18}$ Regarding France, a dramatic drop in similarity has been recorded for trees and other plants (idem for the QSI) and products of the milling industry; instead, the similarity increases for miscellaneous edible preparations (idem for the QSI) and beverages. The similarity with Spain at the sectoral level presents greater variation. We find a drastic increase in sectors such as live animals,

\footnotetext{
${ }^{18}$ As Greece is concerned, edible vegetables, Cocoa and cocoa prep, Prep. of fruit and vegetables, Misc. edible preparations and Beverages present a decline. This evidence is mainly confirmed also in terms of quality. In Portugal sectors as Trees and other plants, Edible vegetables, Prod. of the milling industry and Misc. edible preparations registers a drop in terms of product similarity.
} 
products of animal origin, oils and fats, beverages, residues from food industries, and tobacco; on the other hand, in edible vegetables, cereals, products of the milling industry, oilseeds, and lac/gums/resins the similarity decreases remarkably. Nevertheless, in terms of quality the similarity is fairly constant, except for oils and fats, preparation of meat and fish, and tobacco, for which it rises drastically, and sugar and sugar confectionaries, for which it drops considerably.

The economic crisis seems associated with a slight modification of the exports structure. The degree of similarity in terms of product between Italy and the European Mediterranean countries increased in the first two periods of our analysis, 2005/2006 and 2008/2009, but fell in several cases during the biennium of 2011/2012; by contrast, in terms of quality the similarity drops remarkably in the biennium of 2008/2009; in this regard, a V-shaped trend has been recorded in the North American market in the scrutinized period. These tendencies show that flows that are similar are of different quality. The main result of the analysis is that products are more complementary than similar. In other words, the decreasing QSI for preparation of fruit and vegetables or fruits implies a dissimilarity in terms of quality of products: France and Italy exports products having different quality. It could be that France exports more "Fuji Apple" and Italy more "Golden Apple," or Spain exports "Virgin Olive Oil" and Italy "Extra Virgin Olive Oil.” Therefore, countries address products in different market segments.

\section{Conclusions}

This study investigates the evolution in the similarity of Italian exports compared to other European Mediterranean countries' exports, in the EU and North American markets, before and after the most recent financial crisis. 
Overall, results show that the similarity of the Italian agri-food exports relative to the group of Euro-Mediterranean countries appears heterogeneous depending on the targeted market, the compared country, and the agri-food sub-sector.

When considering "gross" exports and the ES and PSI, the greater degree of similarity with Italy has been recorded for France and Spain, in both the North American and the EU-25 markets. More precisely, in the North American market, the main competitor seems to be France, while in the European market, France and Spain appear to be equivalent.

However, the similarity between Italy and the other European Mediterranean countries is relatively small and drops dramatically considering the QSI. This is particularly true for the North American market, where QSI tends to zero, implying that the products exported are qualitatively dissimilar.

Similarity indexes based on specific agri-food items generally reflect the similarity calculated in the aggregate sector, even though in sporadic cases, the maximum value reached by the QSI is greater than $50 \%$. This suggests that flows, apparently similar, tend to satisfy different market segments; thus, the competition among countries seems decreasing when considering the quality factor. Indeed, Italy is an important stakeholder in the world food system having developed a strong reputation for high quality products, such as pasta, cheese, olive oil, wine, and so on.

Observing exports flows in value added, index values tend to be relatively higher compared to gross exports flows. These results may suggest that the domestic production process is somewhat similar between Euro-Mediterranean countries and Italy. Accordingly, a crucial role in order to further diversify products and become more competitive might be played by innovations in the production process. 


\section{References}

Abd-el-Rahman, K. 1991. 'Firms' Competitive and National Comparative Advantages as Joint Determinants of Trade Composition." Review of World Economics 127 (1): 83-97.

Antimiani, A., and R. Henke. 2007. "Old and New Partners: Similarity and Competition in the EU Foreign Agri-Food Trade1.” Food Economics - Acta Agriculturae Scandinavica, Section C 4 (3): 129-38.

Antimiani, A., and R. Henke, R. 2006, August. Italy and China Agri-Food Trade: Integration, Similarity and Competition. In 2006 Annual Meeting, August 12-18, 2006, Queensland, Australia (No. 25283). International Association of Agricultural Economists.

Antimiani, A., A. Carbone, V. Costantini, and R. Henke. 2012. "Agri-Food Exports in the Enlarged European Union.” ZEMEDELSKA EKONOMIKA 58(8): 354-366.

Aw, B. Y., and M. J. Roberts. 1988. "Price and quality comparisons for US footwear imports: An application of multilateral index numbers." Empirical Methods for International Trade, MIT Press, Cambridge, MA, forthcoming

Berry, S. T. 1994. "Estimating discrete-choice models of product differentiation." The RAND Journal of Economics 242-262. 
Bojnec, S., and I. Fertő. 2010. "Quality differentiation in East-West European agro-food trade during the pre-accession." Transformations in Business \& Economics 9(3): 21.

Bojnec, S. and I. Fertő. 2015. "Agri-Food Export Competitiveness in European Union Countries.” Journal of Common Market Studies 53(3): 476-492.

Crespo, N., and N. Simões. 2012. "On the measurement of a multidimensional concept of structural similarity”. Economics Letters 116(1): 115-117.

Curzi, D., V. Raimondi, , and A. Olper. 2014. "Quality upgrading, competition and trade policy: evidence from the agri-food sector." European Review of Agricultural Economics 42(2): 239-267.

De Benedictis, L., and L. Tajoli. 2007a. "Openness, similarity in export composition, and income dynamics." The Journal of International Trade \& Economic Development 16(1): 93116.

De Benedictis, L., and L. Tajoli. 2007b. Economic integration and similarity in trade structures. Empirica 34(2): 117-137.

De Nardis, S., and F. Traù. (1999). "Specializzazione settoriale e qualità dei prodotti: misure della pressione competitiva dell'industria italiana." Rivista italiana degli economisti 4(2): 177212.

Dedrick, J., K. L. Kraemer, and G. Linden. 2010. "Who profits from innovation in global value chains?: a study of the iPod and notebook PCs." Industrial and corporate change 19(1): 81116.

Di Comite, F., L. Rovegno, H. Vandenbussche, and C. Viegelahn. 2011. "Moving Up the Quality Ladder? EU-China Trade Dynamics in Clothing.” No. 8725. CEPR Discussion Papers. 
Duboz, M. L., and J. Le Gallo. 2011. "Are EU-15 and CEEC agricultural exports in competition? Evidence for 1995-2005.” Economics Bulletin 31(1): 134-146.

European Commission 2009. Report on the Competitiveness of the European Agro-Food Industry. Enterprise and Industry Directorate General, Food Industry Unit. On line: http://ec.europa.eu/enterprise/sectors/food/files/high_level_group_2008/documents_hlg/final _report_hlg_17_03_09_en.pdf .

Feenstra, R. C., and J. Romalis. 2014. "International prices and endogenous quality." The Quarterly Journal of Economics 129(2): 477-527.

Feenstra, R. C., J. Romalis, and P. K. Schott. 2002. "US imports, exports, and tariff data, 1989 2001 (No. w9387).” National Bureau of Economic Research.

Finger, J. M., and M. E. Kreinin. 1979. “A Measure of 'Export Similarity’ and Its Possible Uses." The Economic Journal 89 (356): 905-912.

Fontagné, L., G. Gaulier, and S. Zignago. 2008. "Specialization across varieties and NorthSouth competition.” Economic policy 23(53): 52-91.

Greenaway, D., and C. Milner. 1983. "On the measurement of intra-industry trade." The Economic Journal 93(372): 900-908.

Grubel, H. G., and P. J. Lloyd. 1971. "The Empirical Measurement of Intra-Industry Trade.” Economic record 47(4): 494-517.

Hallak, J. C., and P. K. Schott. 2011. "Estimating cross-country differences in product quality." The Quarterly journal of economics 126(1): 417-474.

Harling, K. 2008. "Competing in a Mature Market: The case of Super AM Food Markets." International Food and Agribusiness Management Review 11(4): 105-126. 
Harding, T., and B. Smarzynska Javorcik. 2009. "A Touch of Sophistication: FDI and Unit values of exports.” No. 2865. CESifo Working Paper.

Hummels, D., and P. J. Klenow. 2005. "The variety and quality of a nation's exports." American Economic Review 95(3): 704-723.

ISTAT (Istituto Nazionale di Statistica). 2014. Rapporto annuale 2014: La situazione del paese.

Javorsek, M., and I. Camacho. 2015. "Trade in value added: Concepts, estimation and analysis" (No. 150). ARTNeT Working Paper Series.

Johnson, R. C. 2014. "Five facts about value-added exports and implications for macroeconomics and trade research." The Journal of Economic Perspectives 28(2): 119-142.

Kaitila, V. 2010. “Quality-adjusted similarity of EU-countries' export structure” (No. 1227). ETLA discussion paper.

Khandelwal, A. 2010. "The long and short (of) quality ladders." The Review of Economic Studies 77(4): 1450-1476.

Khandelwal, A. K., P. K. Schott, and S. Wei. J. 2013. "Trade liberalization and embedded institutional reform: evidence from Chinese exporters." American Economic Review 103(6): 2169-95.

Koopman, R., W. Powers, Z. Wang, and S. J. Wei. 2010. "Give credit where credit is due: Tracing value added in global production chains" (No. w16426). National Bureau of Economic Research.

Koopman, R., Z. Wang, and S. Wei. J. 2008. "How much of Chinese exports is really made in China? Assessing domestic value-added when processing trade is pervasive" (No. w14109). National Bureau of Economic Research. 
Koopman, R., Z. Wang, and S. J. Wei. 2014. "Tracing value-added and double counting in gross exports." The American Economic Review 104(2): 459-494.

Moreira, S., N. Simoes, and N. Crespo. (2017). "A contribution to a multidimensional analysis of trade competition." The World Economy 40(10): 2301-2326.

Pomfret, R. 1981. "The impact of EEC enlargement on non-member Mediterranean countries' exports to the EEC." The Economic Journal 91(363): 726-729.

Qineti, A., M. Rajcaniova, and E. Matejkova. 2009. "The competitiveness and comparative advantage of the Slovak and the EU agri-food trade with Russia and Ukraine." Agricultural Economics - Czech 55(8): 375-383.

Schott, P. K. 2004. "Across-product versus within-product specialization in international trade." The Quarterly Journal of Economics 119(2): 647-678.

Torok, A., and A. Jambor. 2013. "Competitiveness and Geographical Indications: the case of fruit spirits in Central and Eastern European countries." Studies in Agricultural Economics 115(1).

Wubben, E. F., and G. Isakhanyan. 2013. "The wicked problem of promoting sustainability by means of enhanced biomass utilisation." International Food and Agribusiness Management Review 16(A): 1-6.

Zaghini, A. 2005. "Evolution of trade patterns in the new EU member states." Economic of Transition 13(4): 629-658.

Zheng, Y., and J. Qi. 2007. "Empirical Analysis of the Structure of Sino-US Agricultural Trade." China \& World Economy 15(4): 35-51. 